\title{
Understanding the relationship between land use and land cover and malaria in Nepal
}

\author{
Shreejana Bhattarai, ${ }^{1}$ Korine N. Kolivras, ${ }^{1}$ Kabita Ghimire, ${ }^{2}$ Yang Shao ${ }^{1}$ \\ ${ }^{1}$ Department of Geography, Virginia Tech, Blacksburg; ${ }^{2}$ Environmental Services Division, Department of \\ Public Works, Prince William County, Virginia, USA
}

\begin{abstract}
Malaria is a leading cause of mortality and morbidity globally. Land Use and Land Cover (LULC) change have been found to affect the transmission of malaria in other regions, but no study has examined such relationships in Nepal. Therefore, this study has three aims: first, to analyze the spatial and temporal trend of Malaria Incidence Rate (MIR) between 1999 and 2015, second to assess LULC change between 2000 and 2010, and finally to understand the relationship between LULC and malaria in Nepal. The land cover types examined are forest, water bodies, agriculture, grassland, shrubland, barren areas, built-up areas, and rice paddies. The temporal trend of MIR and the relationship between MIR and LULC were evaluated using Poisson and negative binomial regression. Forest, water bodies, and built-up area increased in Nepal by $0.8 \%, 8.2 \%$, and $28.4 \%$ respectively, while other LULC variables decreased between 2000 and 2010. MIR decreased significantly in 21 districts; however, four districts, namely Pyuthan, Kaski, Rupandehi, and Siraha, had a significantly increasing MIR trend between 1999 and 2015. MIR was positively related to water bodies and rice paddies during 2001, 2002, and 2003 but negatively related to grassland during 2010 . However, there was no relationship between LULC and MIR during 2000, 2011, 2012 and 2013. This information will be helpful for public health officials to increase control efforts in those districts and in areas near water bodies and rice paddies to aid in their effort to eliminate malaria from Nepal.
\end{abstract}

Correspondence: Shreejana Bhattarai, Department of Geography, Virginia Tech, Blacksburg, Virginia, 24061, USA

Tel: +1.540 .818 .4869$

E-mail: bshreej@vt.edu

Key words: Malaria Incidence Rate; Land Use and Land Cover; Poisson Regression; Negative Binomial Regression; Nepal.

Conflict of interests: The authors declare no potential conflict of interests.

Received for publication: 2 January 2020.

Accepted for publication: 11 July 2020.

(C) Copyright: the Author(s), 2020

Licensee PAGEPress, Italy

Geospatial Health 2020; 15:855

doi:10.4081/gh.2020.855

This article is distributed under the terms of the Creative Commons Attribution Noncommercial License (CC BY-NC 4.0) which permits any noncommercial use, distribution, and reproduction in any medium, provided the original author(s) and source are credited.

\section{Introduction}

Malaria is one of the most significant public health problems worldwide (CDC, 2017). In 2018, 228 million cases of malaria occurred globally, resulting in 405,000 deaths (WHO, 2019). Sub-Saharan Africa carries the highest share of the malaria burden with $93 \%$ of the cases in 2018 , followed by the South-East Asia region with 3.4\% of the total cases in 2018 (WHO, 2019).

Malaria, caused by the parasite Plasmodium and transmitted by the infected female mosquito of the Anopheles species, is a vector-borne disease that occurs in warm and humid environments. The initial symptoms of the disease, which include chills, fever, and headache, may not be easily identified as malaria. It is a preventable and curable disease; however, it can be life-threatening if not treated in time (WHO, 2019).

The malaria transmission cycle is dependent on environmental factors related to the parasite, the vector, and the human host (WHO, 2018). Land Use and Land Cover (LULC) change are one of the important environmental factors known to influence malaria incidence and transmission (e.g. Lindblade et al., 2000; Ijumba and Lindsay, 2001; Yasuoka and Levins, 2007). Land use change affects the distribution and abundance of vectors through habitat modification and can even influence interactions between human and mosquitoes (Vanwambeke et al., 2007). LULC variables such as forests, water bodies, and agricultural practices such as rice cultivation have been associated with malaria in several studies.

Forests and forests fringes are associated with malaria in Southeast Asia and thus the term forest malaria is commonly used in this region (Prothero, 1999; Bharati and Ganguly, 2013; Dhimal et al., 2014b; Dhimal et al., 2014c, Ghimire, 2016). Water bodies have a positive relationship with malaria transmission as they provide breeding habitats for mosquitoes and typically result in a high mosquito density. Construction of dams in the Ethiopian highlands, Cameroon, the Uasin Gishu Highlands in Kenya, and other areas have resulted in increased malaria transmission due to the formation of large reservoirs behind the dam (Ripert and Raccurt, 1987; Khaemba et al., 1994; Ghebreyesus et al., 1999; Ijumba and Lindsay, 2001). Similarly, agriculture has influenced malaria transmission in different countries. For example, the construction of canal systems for irrigation caused an unprecedented malaria epidemic in 1992 in several villages in the Thar Desert of northwest India (Tyagi and Yadav, 1996 as mentioned in Sarkar et al., 2012). Within agriculture types, rice cultivation is often related to malaria incidence and transmission because rice paddies are flooded with water for a long time and thus provide suitable breeding sites for mosquitoes that transmit malaria. In the rural parts of central Côte d'Ivoire, the density of the principal malarial vector was several-fold higher in irrigated rice paddies than in areas with traditional crop cultivation, including vegetable cultivation 
(Koudou et al., 2005). Similarly, another study in the state of Karnataka in India found that the rice cultivation was associated with increased malaria incidence (Sarkar et al., 2012).

Nepal is also endemic for malaria. Malaria was a significant cause of morbidity and mortality in Nepal throughout much of the 20th century (UCSF, 2015). To prioritize the vector control interventions, Nepal classified its 75 districts into four categories based on Annual Parasite Index (API) in 2010 (DoHS, 2010; DoHS, 2011; Dhimal et al., 2014c). API is the total confirmed malaria cases per 1000 population at risk (DoHS, 2009). Based on this classification, there are 13 high-risk districts (API $>1$ ), 18 moderate-risk districts (API 0.5-1), 34 low-risk districts $(<0.5)$, and 10 no-risk districts (API=0), (EDCD, 2011; Dhimal et al., 2014c). The two major vector control interventions used in Nepal are LongLasting Insecticidal Nets (LLIN) and Indoor Residual Spraying (IRS). LLINs are distributed in high-risk areas through mass distribution and in high-risk and moderate-risk areas through pregnant women during their antenatal care visit to health care institutes (DoHS, 2010). While, IRS is sprayed in selected areas including epidemic outbreak, new settlements and development projects in high-risk malarial areas, epidemic-prone situations, high prevalence of $P$. falciparum cases, and areas with drug-resistant malaria (DoHS, 2010). With the vector control interventions, malaria has been decreasing in Nepal significantly (Dhimal et al., 2014b; Dhimal et al., 2014c) from 42,321 in 1985 (Dhimal et al., 2014c) to 991 in 2015 (DoHS, 2015). However, despite the declining trends, malaria has expanded into new areas which were previously considered non-endemic (Badu, 2013; Bhandari, 2013; Dhimal et al., 2014a; Dhimal et al., 2014b; Ghimire, 2016). Besides, there have been considerable changes in LULC in Nepal over the past few decades (Uddin et al., 2014; Paudel et al., 2016), which can affect the distribution of malaria. However, no study has attempted to understand the association between malaria and LULC in Nepal, and this research intends to fill this research gap. Thus, this study aims to explore whether the Spatio-temporal distribution of malaria in Nepal can be related to LULC variables. The understanding of the links between LULC and incidence of malaria is of critical importance to initiate effective policies for disease control. The results of this study will inform government and public health officials about the association of these environmental variables with malaria and will aid in the planning of control efforts. Such information is vital for Nepal as it is aiming to be malaria-free by 2026 (DoHS, 2015).

\section{Materials and methods}

\section{Study area}

Nepal is a small mountainous country in the central Himalayas with an area of $147,181 \mathrm{~km}^{2}$ and a population of $26,494,504$ in 2011 (CBS, 2014). It is a landlocked country bordering China in the north and India on the other sides (Figure 1). It extends up to $800 \mathrm{~km}$ in length while breadth varies from $90-200 \mathrm{~km}$. Within this relatively short distance, the elevation varies greatly from about 60 meters above sea level in the south to $8848.86 \mathrm{~m}$ (at the summit of Mt. Everest) in the north. Based on the elevation variation, Nepal is broadly divided into three ecological regions: Tarai, Hill, and Mountain.

The Tarai region that lies in the southernmost part of the country, ranges between 70 meters to 1000 meters. The land use types of the region mostly consist of cultivated land, forests, swamps, and urban areas (Ghimire, 2016). The climate is subtropical or tropical, making malaria-endemic because the climate is suitable for mosquito survival and reproduction. The Hill region ranges between 500 meters to 3000 meters. The major land use types of the region are forest, cultivated area, shrublands, and urban areas (Ghimire, 2016). The Hill region has a temperate climate that supports year-round mosquito survival and reproduction (Ghimire, 2016). Finally, the Mountain region lies in the northernmost part of the country. The elevation ranges between 3000 meters to 8848.86 meters. The land cover types of the area are grazing lands, rocks, rocky outcrop, forest and permanent snow and ice (Ghimire, 2016). The Mountain region, having an alpine to sub-alpine cli-

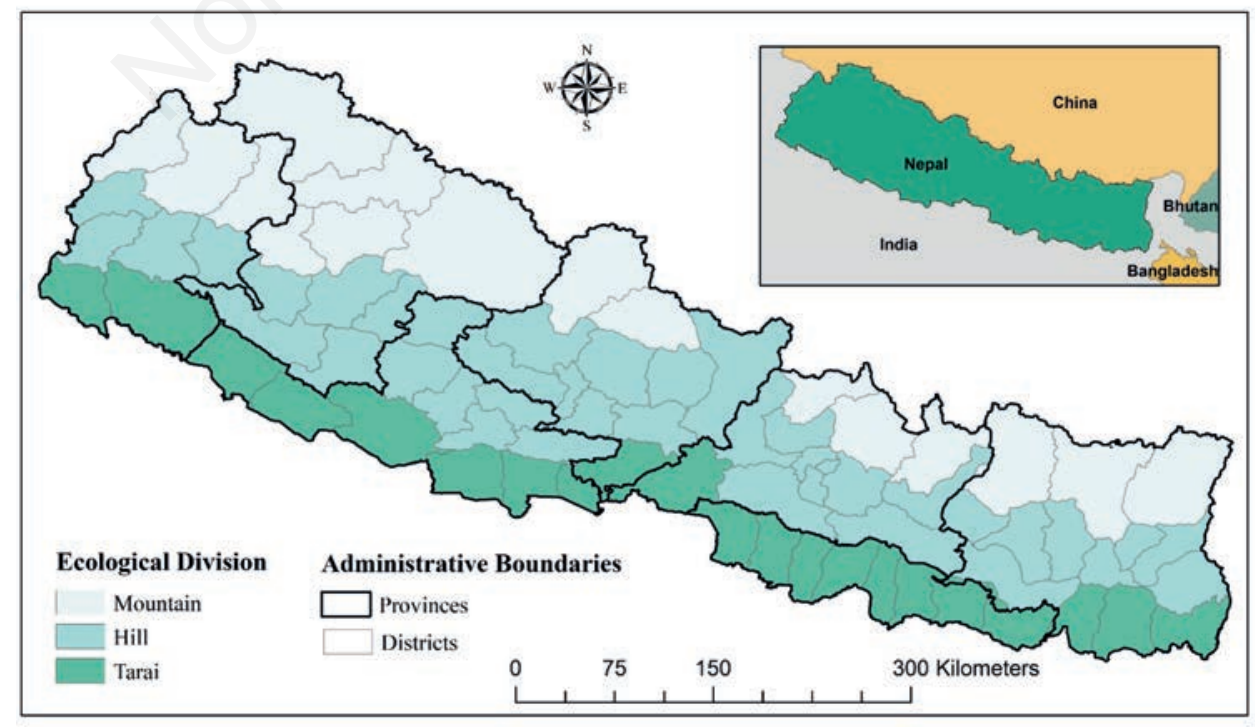

Figure 1. Major ecological and administrative division of Nepal. 
mate, is generally less hospitable for mosquito survival. For administrative purpose, Nepal was divided into five development regions, 14 zones, 75 districts, 130 municipalities, and 3,833 Village Development Committees (VDCs), (CBS, 2014; Aksha et al., 2018). With the commencement of a new constitution in 2015, Nepal is now divided into seven provinces, and 753 various local bodies (including six metropolitan cities, 11 submetropolitan cities, 276 municipalities, and 460 rural municipalities), (Aksha and Emrich, 2020). This study is based on previous administrative units: the districts because the malaria data was available for districts.

\section{Data}

Three datasets were used for the study: malaria cases, population data, and land use and land cover (LULC) data. The available online record of annual indigenous malaria cases from 1999 to 2015 were obtained from the annual reports of the Department of Health Services of the Government of Nepal (DoHS, 19992013). The data included cases caused by both Plasmodium vivax and Plasmodium falciparum. Out of 75 districts, only 58 districts were included in the study because 11 districts, mostly located in the Mountain region, did not have any indigenous malaria cases and six districts had five years or fewer with malaria cases during the study period of 1999 to 2015. The districts with no indigenous malaria cases are Solukhumbu, Myagdi, Manang, Mustang, Humla, Rasuwa, Nuwakot, Kathmandu, Bhaktapur, Dolakha and Jajarkot. The six districts with malaria cases for less than five years are Rolpa, Baglung, Khotang, Dolpa, Mugu and Darchula.

Population data for census years 2001 and 2011 were obtained for each district from the Central Bureau of Statistics (CBS), Nepal (CBS, 2014). The population for non-census years between 2001 and 2011 was extrapolated based on the population growth rate of the census years.

The raster layers of land use and land cover data prepared using public domain Landsat TM were downloaded from the International Centre for Integrated Mountain Development (ICIMOD) geoportal for the years 2000 and 2010. This dataset has a spatial resolution of $30 \mathrm{~m}$ and has been classified into eight classes: forest, shrubland, grassland, agriculture, barren area, water bodies, snow/glacier cover, and built-up area. Classification categories are the same for both years. Additionally, the area of rice paddies for all districts was obtained from the publications of Ministry of Agricultural Development (MoAD), Government of Nepal for 2000 and 2010 (MoAD, 2013). In addition to the agriculture land cover category, we also used rice paddies as an additional LULC variable to understand its relationship with malaria in Nepal. Many studies have shown that rice cultivation is associated with increased malaria transmission (Sharma et al., 1994; Ijumba and Lindsay, 2001; Koudou et al., 2005; Jarju et al., 2009). This is because rice paddies are flooded with water for a long duration which provides elongated period of suitable breeding habitats for mosquitoes.

\section{Data preparation}

\section{Malaria incidence rate}

For the data analysis, MIR was used instead of malaria case data because MIR uses the total population of the district and thus considers district wise differences in population across time and space. MIR was calculated by dividing the malaria case data by population for each district in each year. The formula used for calculating MIR was:

$$
\text { MIR }=\frac{\text { Malaria case of a district }}{\text { Population of that district }} * 10,000
$$

\section{LULC data}

The percentage of each of the seven classes of LULC from ICIMOD data (forest, shrubland, grassland, agriculture, barren area, water bodies, and built-up area) was calculated for all districts for the years 2000 and 2010 using zonal statistics as table in ArcGIS 10.4.1 (ESRI, Redland, CA). Area of rice paddies for all districts obtained from MoAD reports were converted into percentages. The change in percentage of each LULC variable between 2000 and 2010 was calculated for all districts. The change in LULC for all of Nepal was then calculated by taking a sum of the changes in all districts.

\section{Poisson regression and negative binomial regression}

The temporal trend of MIR from 1999 to 2015 and the relationship between MIR and LULC variables were quantified using Poisson regression and negative binomial regression because they are most appropriate for count data (Evans and Adenomon, 2014). Poisson regression and negative binomial regression models are two different sub-types of Generalized Linear Models (GLM). They are used for data that have probability distributions different from a normal distribution (Kakchapati and Ardkaew, 2011; Evans and Adenomon, 2014; Jumi, 2017). A Poisson regression model is commonly used for modelling the number of cases of a disease in a specific population within a certain time (Kakchapati and Ardkaew, 2011; Jumi, 2017). In Poisson regression, the response variable follows a Poisson distribution (Jumi, 2017), meaning its variance is equal to its mean (Kakchapati and Ardkaew, 2011). When the variance is greater than the mean, the data is over-dispersed, and the Poisson model is not appropriate for that data (Kakchapati and Ardkaew, 2011). Disease count data are often over-dispersed because of clustering (Kakchapati and Ardkaew, 2011; Jumi, 2017). In such case, negative binomial regression is more appropriate because it contains an extra parameter that allows the variance of the data to exceed its mean, i.e. it allows for the over-dispersion (Kakchapati and Ardkaew, 2011; Jumi, 2017). Several studies have used Poisson and negative binomial regression to understand malaria trends. For example, Kakchapati and Ardkaew (2011) used negative binomial regression to model malaria incidence rates from 1998 to 2009 in Nepal. They found a decreasing MIR trend in Nepal between 1998 and 2004, then a moderately increasing trend until 2008, and then again, a decreasing trend after 2008. Jumi (2017) studied the trend of malaria incidence in Jubek state, South Sudan using Poisson and negative binomial regression and found that malaria incidence increased by $0.3 \%$ per week between January 2011 and October 2015. Similarly, studied the trend of malaria prevalence in Minna, Niger state using Poisson and negative binomial regression. They found that malaria prevalence increased by approximately $6 \%$ every month from 2008 to 2012.

Poisson regression was used first when there was no over dispersion of the data, and if the result showed the over-dispersion of the data, then negative binomial regression was used. Statistical analyses were performed in JMP Pro 13 (SAS Institute, Cary, NC). 
Temporal trend analysis was performed for all districts individually using Poisson and negative binomial regression to determine if MIR was increasing or decreasing with time. In this analysis, the response variable was the MIR, and the explanatory variable was the time in years (1999-2015) coded from 0 to 16.

The relationship between MIR and LULC variables was also analyzed using Poisson regression and negative binomial regression. In this analysis, MIR was the response variable, and the different LULC variables were the explanatory variables. This analysis was done based on two LULC maps of 2000 and 2010. For the 2000 LULC map, we evaluated its relationship with 2000, 2001, 2002, and 2003 MIR rates individually i.e. the relationship of 2000 MIR rate with 2000 LULC map; 2001 MIR rate with 2000 LULC map; 2002 MIR rate with 2000 LULC map and so on. For the 2010 LULC map, we evaluated its relationship with 2010, 2011, 2012, and 2013 MIR rates (Table 1). We included multiple MIR years for each LULC map because we assumed that the LULC condition may have impacts on mosquito reproduction and survival for both current and the next two-three years. Moreover, we also assumed that comparing the MIR and LULC only in 2000 and 2010 would not be enough to understand the relationship.

\section{Results}

\section{Trend of malaria incidence rate}

Indigenous MIR decreased significantly from 206.2 in 1999 to 10.45 in 2015 in Nepal (Figure 2). However, to understand if this was true for all districts, we carried out a trend analysis of MIR for all 58 districts individually. Among 58 districts, 25 had statistically significant trends of MIR, indicating that MIR was either increasing or decreasing with time. Among the 25 districts, Poisson regression gave statistically significant trends for 20 districts, and negative binomial regression gave statistically significant trends for five districts. For the rest of the districts, neither method resulted in statistically significant trends. The results (Figure 3, Table 2) showed that 21 districts experienced a statistically significant $(\mathrm{p}<$ 0.05) decreasing trend of MIR between 1999 and 2015. However, four districts, namely Kaski, Pyuthan, Rupandehi, and Siraha, experienced a statistically significant $(\mathrm{P}<0.05)$ increasing trend of MIR during the study period.

\section{Land use and land cover and malaria incidence rate}

Significant LULC change occurred in Nepal between 2000 and 2010 (Table 3). Among the LULC variables, built-up areas increased by $28.4 \%$ over ten years. Other LULC variables, like the forest, increased by $0.82 \%$ while grassland decreased by $8.04 \%$. Agriculture land decreased by $1.61 \%$, rice paddies decreased by $1.51 \%$, and water bodies increased by $8.17 \%$.

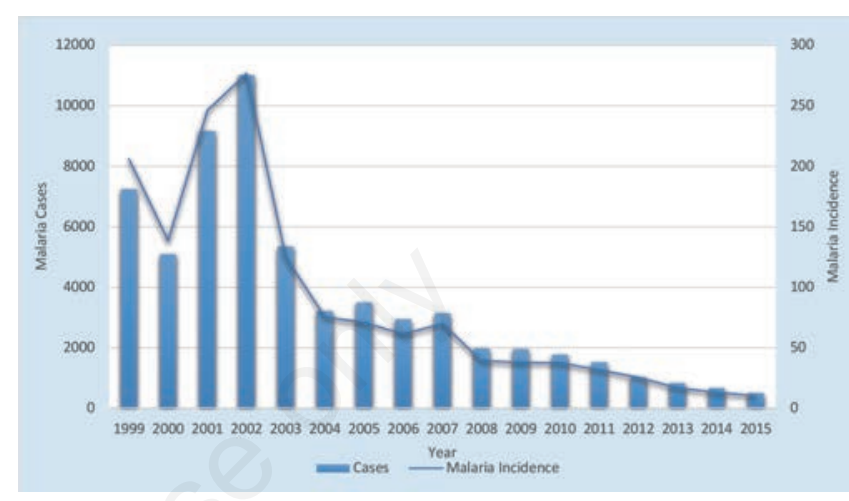

Figure 2. Annual malaria cases and malaria incidence rate in Nepal from 1999 to 2015; Data source: DoHS (1999-2015).

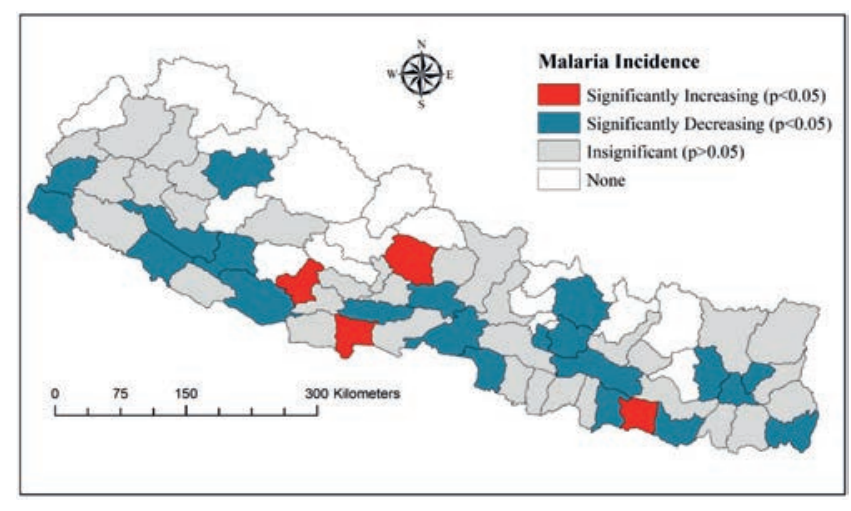

Figure 3. Districts with significantly increasing and decreasing trends of MIR.

Table 1. Regression model for relationship between LULC and MIR.

\begin{tabular}{|c|c|c|c|}
\hline Time period & Response variable & Explanatory variable & Regression model \\
\hline \multirow[t]{4}{*}{2000} & MIR 2000 & LULC 2000 & Poisson/Negative Binomial \\
\hline & MIR 2001 & LULC 2000 & Poisson/Negative Binomial \\
\hline & MIR 2002 & LULC 2000 & Poisson/Negative Binomial \\
\hline & MIR 2003 & LULC 2000 & Poisson/Negative Binomial \\
\hline \multirow[t]{4}{*}{2010} & MIR 2010 & LULC 2010 & Poisson/Negative Binomial \\
\hline & MIR 2011 & LULC 2010 & Poisson/Negative Binomial \\
\hline & MIR 2012 & LULC 2010 & Poisson/Negative Binomial \\
\hline & MIR 2013 & LULC 2010 & Poisson/Negative Binomial \\
\hline
\end{tabular}


MIR of 2000 had no significant relationship with any LULC variables while MIR of 2001, 2002 and 2003 had a significant positive relationship with water bodies and rice paddies. During 2010, the relationship changed and only grassland was significant LULC variable for MIR. The relationship again changed during 2011, 2012 and 2013 when MIR of these three years had no significant relationship with any LULC variables (Table 4). So, the relationship between LULC and MIR have changed over time.

To understand if there are differences in LULC conditions in districts that had statistically significant increasing MIR (increasing districts hereafter) and districts that had statistically significant decreasing MIR (decreasing districts hereafter), we compared the average LULC percentage in four districts with increasing MIR and 21 districts with decreasing MIR. The results showed that rice paddies are greater in increasing districts as compared to decreasing districts (Table 5). The grasslands are about double the percentage in decreasing districts than in increasing districts. However, the percentage of water bodies was slightly higher in decreasing districts than the increasing.

Besides rice paddies, grassland, and water bodies, the difference between forests and agricultural land were also distinct between increasing and decreasing districts. Agricultural lands were higher in percentage in increasing districts than in decreasing districts. Similarly, forests were higher in percentage in decreasing districts than in increasing ones.

\section{Discussion}

In this study, we assessed LULC change between 2000 and 2010, analyzed the spatial and temporal trend of MIR between 1999 and 2015, and examined the relationship between LULC and malaria in Nepal. Our results showed that significant LULC change occurred in Nepal between 2000 and 2010. Over the ten

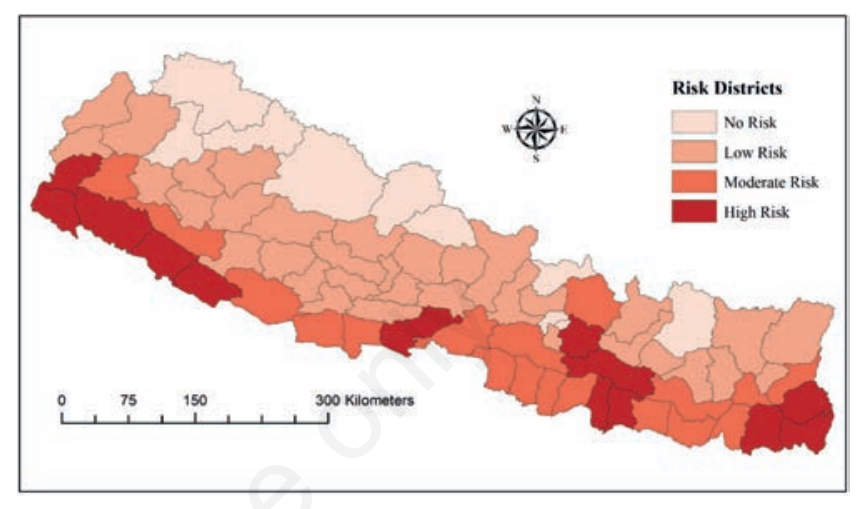

Figure 4. Classification of districts with different risk of malaria by DoHS (DoHS, 2011).

Table 2. Districts with statistically significant increasing/decreasing trends of MIR.

\begin{tabular}{|c|c|c|c|c|c|c|c|}
\hline District & MIR 1999 & $\begin{array}{l}\text { Maximum reported } \\
\text { MIR (Year) }\end{array}$ & MIR 2015 & $\begin{array}{l}\text { MIR Increasing/ } \\
\text { Decreasing }\end{array}$ & $\begin{array}{l}\text { Regression } \\
\text { model }\end{array}$ & Coefficient & P value \\
\hline Bardiya & 17.48 & 23.05 (2001) & 0.31 & Decreasing & Poisson & -0.25 & $<.01$ \\
\hline Bhojpur & 8.6 & $8.6(1999)$ & 0 & Decreasing & Poisson & -0.45 & $<.01$ \\
\hline Chitwan & 0.95 & $1.02(2001)$ & 0.09 & Decreasing & Poisson & -0.18 & $<.01$ \\
\hline Dang & 2.22 & $5.58(2001)$ & 0.12 & Decreasing & Poisson & -0.23 & $<.01$ \\
\hline Dhanusa & 17.23 & $17.23(1999)$ & 0.10 & Decreasing & Negative Binomial & -0.21 & $<.01$ \\
\hline Jhapa & 4.06 & 18.07 (2005) & 0.29 & Decreasing & Negative Binomial & -0.11 & $<.01$ \\
\hline Jumla & 0.69 & $1.14(2000)$ & 0 & Decreasing & Poisson & -0.29 & $<.01$ \\
\hline Kanchanpur & 20.17 & $59.81(2003)$ & 0.35 & Decreasing & Negative Binomial & -0.25 & $<.01$ \\
\hline Parsa & 0.43 & $0.43(1999)$ & 0 & Decreasing & Poisson & -0.63 & $<.01$ \\
\hline Saptari & 2.05 & $1.9(2000)$ & 0.12 & Decreasing & Poisson & -0.139 & $<.01$ \\
\hline Terhathum & 2.16 & $2.74(2004)$ & 0 & Decreasing & Poisson & -0.28 & $<.01$ \\
\hline Dhankuta & 9.43 & 9.43 (1999) & 0 & Decreasing & Negative Binomial & -0.29 & $<.01$ \\
\hline Sindhupalchok & 0.85 & $2.45(2003)$ & 0 & Decreasing & Poisson & -0.23 & $<.01$ \\
\hline Dadeldhura & 4.37 & 11.42 & 0.54 & Decreasing & Poisson & -0.11 & $<.01$ \\
\hline Surkhet & 12.77 & 12.77 (1999) & 0.82 & Decreasing & Poisson & -0.11 & $<.01$ \\
\hline Salyan & 1.79 & 1.79 (1999) & 0 & Decreasing & Poisson & -0.54 & $<.01$ \\
\hline Palpa & 1.07 & 1.07 (1999) & 0.12 & Decreasing & Poisson & -0.1 & $<.01$ \\
\hline Tanahu & 0.13 & 0.13 (1999) & 0 & Decreasing & Poisson & -0.25 & $<.01$ \\
\hline Kavre & 73.4 & 73.4 (1999) & 0 & Decreasing & Poisson & -0.61 & $<.01$ \\
\hline Lalitpur & 1.13 & $1.49(2002)$ & 0 & Decreasing & Poisson & -0.35 & $<.01$ \\
\hline Sindhuli & 7.04 & $8.09(2000)$ & 0.63 & Decreasing & Poisson & -0.19 & $<.01$ \\
\hline Kaski & 0.14 & 0.41 (2013) & 0.04 & Increasing & Poisson & 0.16 & .02 \\
\hline Pyuthan & 0 & $0.55(2006)$ & 0.26 & Increasing & Poisson & 0.285 & $<.01$ \\
\hline Rupandehi & 0 & 1.36 (2010) & 0.66 & Increasing & Poisson & 0.132 & $<.01$ \\
\hline Siraha & 0.04 & $0.99(2006)$ & 0.32 & Increasing & Poisson & 0.115 & .01 \\
\hline
\end{tabular}


years, built-up areas increased by $28.4 \%$; agriculture land decreased by $1.61 \%$; rice paddies have decreased by $1.51 \%$ while water bodies have increased by $8.17 \%$. The trend analysis showed that 21 districts had a significantly decreasing MIR while four districts had a significantly increasing trend of MIR between 1999 and 2015. The study further found that the MIR of 2001, 2002 and 2003 had a significant positive relationship with water bodies and rice paddies, and the MIR of 2010 had a significant negative relationship with grassland. However, the MIR of 2000, 2011, 2012 and 2013 had no significant relationship with any LULC variables. So, the LULC variables associated with MIR have changed over

Table 3. Change in LULC between 2000 and 2010.

\begin{tabular}{lccc} 
LULC Variable & $\begin{array}{c}2000 \\
\text { Area } \\
\text { in sq. km }\end{array}$ & $\begin{array}{c}2010 \\
\text { Area } \\
\text { in sq. km }\end{array}$ & $\begin{array}{c}\text { Percentage } \\
\text { change }\end{array}$ \\
Forest & 61481.99 & 62038.62 & 0.82 \\
Shrubland & 3466.23 & 3430.49 & -1.11 \\
\hline Grassland & 16745.72 & 15412.77 & -8.04 \\
Agriculture & 41007.28 & 40379.93 & -1.61 \\
\hline Barren Area & 14054.05 & 12596.15 & -10.45 \\
Water bodies & 725.24 & 785.18 & 8.17 \\
\hline Built-up Area & 423.01 & 543.6 & 28.4 \\
Rice Paddy & 14449.55 & 14231.65 & -1.51 \\
\hline
\end{tabular}

time. Our result of the trend analysis that most of the districts had a significantly decreasing MIR are consistent with the general trend of decreasing malaria across the country as a whole (Dhimal et al., 2014c). The declining trend is a very encouraging result for the malaria control program as Nepal is preparing for malaria elimination. However, our results showed that four districts, namely Kaski, Pyuthan, Rupandehi and Siraha, had a significantly increasing trend of MIR during the study period. This result differs from the study done by Kakchapati and Ardkaew (2011) in which they found that MIR was higher than average in Kailali, Kanchanpur, Bardiya, Jhapa and Kavre districts. The difference might be due to more longitudinal datasets (1999 - 2015) used in our study than by Kakchapati and Ardkaew (2011), (1998 - 2009).

The malaria control efforts are mainly concentrated in highrisk districts, followed by moderate-risk districts, with the remaining districts receiving less or no attention (DoHS, 2011; DoHS, 2017). Among these four districts with an increasing MIR trend, Rupandehi and Siraha are located within the Tarai region while Kaski and Pyuthan are in the Hill region. The four districts do not fall into the category of high-risk malaria districts, according to the Department of Health Services (DoHS) in Nepal (Figure 4), (DoHS, 2013). Kaski and Pyuthan fall into low-risk districts while Rupandehi and Siraha fall into moderate-risk districts. Thus, this result is very important and should be considered in program and policy formulation process as some moderate-risk and low-risk districts, which get less malaria control interventions, are showing a statistically significantly increasing MIR trend.

Our study also found that the relationship between LULC vari-

Table 4. Relationship between LULC variables and MIR.

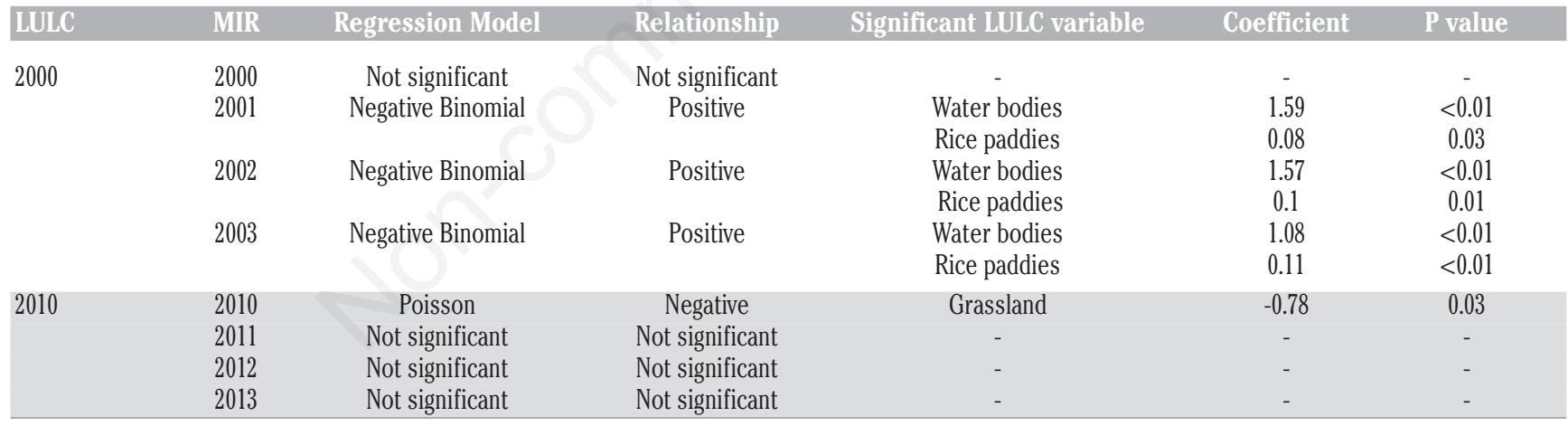

Table 5. Average LULC percentage in MIR increasing and decreasing districts.

\begin{tabular}{lcccc} 
LULC variables & $\begin{array}{c}\text { Average value for statistically significant } \\
\text { increasing districts }\end{array}$ & 2010 & $\begin{array}{c}\text { Average value for statistically significant } \\
\text { decreasing districts }\end{array}$ \\
& 2000 & 51.87 & 2000 & 2010 \\
Agriculture & 52.91 & 3.19 & 38.81 & 38.60 \\
Barren area & 2.73 & 0.61 & 0.59 & 2.58 \\
\hline Built-up area & 0.54 & 34.43 & 50.94 & 0.77 \\
Forest & 33.74 & 2.65 & 4.38 & 51.27 \\
\hline Grassland & 2.41 & 1.74 & 1.19 & 4.03 \\
Shrubland & 1.61 & 0.46 & 0.73 & 1.17 \\
Water body & 0.58 & 26.70 & 16.99 & 0.83 \\
Rice paddy & 31.07 & & & 16.24 \\
\hline
\end{tabular}


ables and MIR have changed over time. None of the LULC variables were associated with MIR of 2000. MIR of 2001, 2002 and 2003 had a significant positive relationship with water bodies and rice paddies. Water bodies and rice paddies provide favourable breeding sites for mosquitoes, which may explain this positive relationship. These findings are similar to other research that found a positive relationship between malaria and water bodies and rice cultivation (Ripert and Raccurt, 1987; Khaemba et al., 1994; Ghebreyesus et al., 1999; Ijumba and Lindsay, 2001; Koudou et al., 2005; Sarkar et al., 2012). The MIR of 2010 had significant negative relationship with grassland. The negative relationship between MIR and grassland may indicate that grassland is not a suitable habit for mosquitoes. The relationship again changed during 2011, 2012 and 2013 as there was no significant relationship of MIR of 2011, 2012 and 2013 with any LULC variables. The lack of relationship between MIR and LULC variables during 2011, 2012 and 2013 may be because the MIR is decreasing overall, and thus the influence of LULC variables is also decreasing. Our findings are similar to what researchers have found in countries like Tanzania and Gambia in Africa. According to these studies, in endemic areas, the introduction of crop irrigation had little or no impact on malaria transmission (Ijumba and Lindsay, 2001; Koudou et al., 2005). In fact, in some sites, malaria transmission was lower in irrigated communities than in surrounding areas, even though there were more mosquitoes (Ijumba and Lindsay, 2001). The lower malaria transmission was due to two reasons: a) the increased use of anti-malarial drugs and carefully planned malaria control activities in the endemic regions; b) the economic growth brought about by the production and sale of rice which improved the standard of living of the people, who could then afford bed nets and other control measures to protect themselves from mosquitoes (Ijumba and Lindsay, 2001). Another study in Sri Lanka also found that irrigated rice cultivation areas had a lower incidence of malaria than non-irrigated areas possibly because of the differences in the socio-economic status of those areas (Klinkenberg et al., 2004). This explanation can potentially apply to Nepal as well. As malaria control efforts have been scaled up in recent decades, mainly in high-risk districts, the MIR is decreasing drastically in those areas. Thus, the LULC variables now have less influence on malaria incidence or transmission. However, as there are fewer malaria control efforts in moderate and low-risk districts, some of them are showing a statistically significant MIR increase, which might be related to LULC. To understand if there are differences in LULC conditions in increasing and decreasing districts, we compared the LULC percentage in four MIR increasing and $21 \mathrm{MIR}$ decreasing districts. Rice paddies have been decreased by $1.51 \%$ in the whole country. Similarly, they have decreased by about $4 \%$ in increasing districts, and by about a percentage in decreasing districts. Rice paddies are much higher in percentage in increasing districts as compared to decreasing districts. It might be the reason behind increasing MIR in four districts as compared to other 21 districts. Similarly, the finding that grasslands are about double the percentage in decreasing districts than in increasing districts also are consistent with the negative relationship between grassland and MIR in our previous result. However, water bodies were slightly higher in percentage in decreasing districts than in increasing districts, thus contradicting our result of the positive relationship between water bodies and MIR. However, this comparison is based on average values of LULC variables in increasing and decreasing districts, and thus the relationship can be different spatially in each district. Unexpected findings from the study include the lack of relationship of MIR with forests. The high incidence or presence of malaria near the forest belts in Nepal has been mentioned in several previous studies (WHO, 2011; DoHS, 2014; Sherchand et al., 1996 as mentioned in Ghimire, 2016). However, we did not find any significant relationship between forests and MIR.

Several limitations were present in this study. Analyses were conducted using the annual district-wise MIR that was available online. The malaria data from lower administrative units like municipalities and Village Development Committees (VDCs) reported weekly and monthly could provide an improved understanding of the spatial and temporal malaria trend as well as its relationship between LULC variables. A second limitation of the study is that we have compared the total MIR of the district with the total percentage of each category of LULC in that district as we did not have the spatial location of individual malaria cases. The analysis including fine-scale locations of both LULC and MIR might give a different result. Furthermore, future studies can also utilize high resolution remote sensing to classify land cover at a finer scale to identify mosquito breeding habitats including rice fields and pools of water. Then interventions can be targeted in such breeding habitats to control malaria. An additional limitation of this research is that it has only used LULC variables as explanatory variables for the malaria incidence. Additional factors that can affect malaria include climate change, impacts of control efforts, changes in socio-economic conditions of the people, distance to health facilities, migration, and others. Thus, further research should incorporate these factors into a more holistic study.

\section{Conclusions}

This study has important findings that improve our understanding of the changing relationship between LULC and malaria in Nepal. The findings show that there was a significant positive relationship of MIR with water bodies and rice paddies in 2001, 2002 and 2003; a significant negative relationship with grassland in 2010; and no relationship with any LULC variable in 2000, 2011, 2012 and 2013. The study also found a significant change in LULC in Nepal between 2000 and 2010. Moreover, the study also found that, contrary to the general trend of decreasing MIR in the country, four districts, namely Pyuthan, Kaski, Rupandehi and Siraha, had a statistically significant $(\mathrm{P}<0.05)$ increasing trend of MIR between 1999 and 2015 .

The information regarding LULC features with a positive relationship with MIR and the four districts with an increasing MIR trend will be important for public health officials. It will help them to increase control efforts in those districts and in areas near water bodies and rice paddies to aid in their effort to eliminate malaria from Nepal. LULC change influence mosquito populations and disease transmission risk, but transmission can be prevented through control efforts and increased awareness among the people. Vanwambeke et al. (2007) also suggested that control efforts and education campaigns can reduce effects caused by LULC change.

\section{References}

Aksha SK, Juran L, Resler, LM, 2018. Spatial and temporal analysis of natural hazard mortality in Nepal. Environ Hazards 17:163-179. 
Aksha SK, Emrich CT, 2020. Benchmarking community disaster resilience in Nepal. Int J Environ Res Public Health 17:1985.

Badu M, 2013. Assessing the impact of climate change on human health: status and trends of malaria and diarrhea with respect to temperature and rainfall variability in Nepal. Kath Uni J Sci Engi Tech 9:96-105.

Bhandari GP, Dhimal M, Gurung S, Bhusal C, 2013. Climate Change and Malaria in Jhapa District of Nepal: Emerging Evidences from Nepal. J Health Manage 15:141-150.

Bharati K, Ganguly NK, 2013. Tackling the malaria problem in the South-East Asia Region: need for a change in policy? Indian $\mathrm{J}$ Med Res 137: 36-47.

Central Bureau of Statistics (CBS), 2014. Population monograph of Nepal Volume II. Central Bureau of Statistics, Kathmandu, Nepal. Available from: https://nepalindata.com/resource/population-monograph-of-nepal-volume-ii-social-demography/ Accessed on: April 2017

Central for Disease Control and Prevention (CDC), 2017. Malaria. World Health Organization, Geneva, Switzerland. Available from: https://www.cdc.gov/malaria/ Accessed on: April 2017.

Dhimal M, Ahrens B, Kuch U, 2014a. Altitudinal shift of malaria vectors and malaria elimination in Nepal. Malar J 13:26.

Dhimal M, O'Hara RB, Karki R, Thakur GD, Kuch U, Ahrens B, 2014b. Spatio-temporal distribution of malaria and its association with climatic factors and vector-control interventions in two high-risk districts of Nepal. Malar J 13:457.

Dhimal M, Ahrens B, Kuch U, 2014c. Malaria control in Nepal 1963-2012: challenges on the path towards elimination. Malar J 13:241.

Department of Health Services (DoHS), 1999. Annual Report 2056/57 (1999/2000). Department of Health Services, Ministry of Health and Population, Government of Nepal, Kathmandu. Available from: https://dohs.gov.np/publications/ Accessed on: February 2017.

Department of Health Services (DoHS), 2000. Annual Report 2057/58 (2000/2001). Department of Health Services, Ministry of Health and Population, Government of Nepal, Kathmandu. Available from: https://dohs.gov.np/publications/ Accessed on: February 2017.

Department of Health Services (DoHS), 2001. Annual Report 2058/59 (2001/2002). Department of Health Services, Ministry of Health and Population, Government of Nepal, Kathmandu. Available from: https://dohs.gov.np/publications/ Accessed on: February 2017.

Department of Health Services (DoHS), 2002. Annual Report 2059/60 (2002/2003). Department of Health Services, Ministry of Health and Population, Government of Nepal, Kathmandu. Available from: https://dohs.gov.np/publications/ Accessed on: February 2017.

Department of Health Services (DoHS), 2003. Annual Report 2060/61 (2003/2004). Department of Health Services, Ministry of Health and Population, Government of Nepal, Kathmandu. Available from: https://dohs.gov.np/publications/ Accessed on: February 2017.

Department of Health Services (DoHS), 2004. Annual Report 2061/62 (2004/2005). Department of Health Services, Ministry of Health and Population, Government of Nepal, Kathmandu. Available from: https://dohs.gov.np/publications/ Accessed on: February 2017.

Department of Health Services (DoHS), 2005. Annual Report 2062/63 (2005/2006). Department of Health Services,
Ministry of Health and Population, Government of Nepal, Kathmandu. Available from: https://dohs.gov.np/publications/ Accessed on: February 2017.

Department of Health Services (DoHS), 2006. Annual Report 2063/64 (2006/2007). Department of Health Services, Ministry of Health and Population, Government of Nepal, Kathmandu. Available from: https://dohs.gov.np/publications/ Accessed on: February 2017.

Department of Health Services (DoHS), 2007. Annual Report 2064/65 (2007/2008). Department of Health Services, Ministry of Health and Population, Government of Nepal, Kathmandu. Available from: https://dohs.gov.np/publications/ Accessed on: February 2017.

Department of Health Services (DoHS), 2008. Annual Report 2065/66 (2008/2009). Department of Health Services, Ministry of Health and Population, Government of Nepal, Kathmandu. Available from: https://dohs.gov.np/publications/ Accessed on: February 2017.

Department of Health Services (DoHS), 2009. Annual Report 2066/67 (2009/2010). Department of Health Services, Ministry of Health and Population, Government of Nepal, Kathmandu. Available from: https://dohs.gov.np/publications/ Accessed on: February 2017.

Department of Health Services (DoHS), 2010. Annual Report 2067/68 (2010/2011). Department of Health Services, Ministry of Health and Population, Government of Nepal, Kathmandu. Available from: https://dohs.gov.np/publications/ Accessed on: February 2017.

Department of Health Services (DoHS), 2011. Annual Report 2068/69 (2011/2012). Department of Health Services, Ministry of Health and Population, Government of Nepal, Kathmandu. Available from: https://dohs.gov.np/publications/ Accessed on: February 2017.

Department of Health Services (DoHS), 2012. Annual Report 2069/70 (2012/2013). Department of Health Services, Ministry of Health and Population, Government of Nepal, Kathmandu. Available from: https://dohs.gov.np/publications/ Accessed on: February 2017.

Department of Health Services (DoHS), 2013. Annual Report 2070/71 (2013/2014). Department of Health Services, Ministry of Health and Population, Government of Nepal, Kathmandu. Available from: https://dohs.gov.np/publications/ Accessed on: February 2017.

Department of Health Services (DoHS), 2014. Annual Report 2071/72 (2014/2015). Department of Health Services, Ministry of Health and Population, Government of Nepal, Kathmandu. Available from: https://dohs.gov.np/publications/ Accessed on: February 2017.

Department of Health Services (DoHS), 2015. Annual Report 2072/73 (2015/2016). Department of Health Services, Ministry of Health and Population, Government of Nepal, Kathmandu. Retrieved from https://dohs.gov.np/publications/ on February, 2017.

Department of Health Services (DoHS), 2017. Annual Report 2074/75 (2017/2018). Department of Health Services, Ministry of Health and Population, Government of Nepal, Kathmandu. Available from: https://dohs.gov.np/publications/ Accessed on: December 2019.

Epidemiology and Disease Control Division (EDCD), 2011. Nepal Malaria Strategic Plan 2011-2016 (Revised VersionDecember 2011). Epidemiology and Disease Control Division, 
Department of Health Services, Ministry of Health and Population, Government of Nepal, Kathmandu. Available from: http://static1.1.sqspcdn.com/static/f/471029/20810332/ 1351638302043/Nepal+Strategic+Plan+2011-1016.pdf?token =nWYAdQ7Y9YMVX0ydfBODxHdOxFQ\%3D Accessed on: April 2020.

Evans OP, Adenomon MO, 2014. Modelling the prevalence of malaria in Niger State: An application of Poisson regression and negative binomial regression models. Int J Phys Sci 2:618.

Ghebreyesus TA, Haile M, Witten KH, Getachew A, Yohannes AM, et al., 1999. Incidence of malaria among children living near dams in northern Ethiopia: community based incidence survey. BMJ 319:663-6.

Ghimire K, 2016. Geographic distribution of malaria in Nepal (Unpublished doctoral dissertation). Available from: https://krex.k-state.edu/dspace/bitstream/handle/2097/34464/ KabitaGhimire2016.pdf? sequence $=5$ Accessed on: February, 2017.

Ijumba JN, Lindsay SW, 2001. Impact of irrigation on malaria in Africa: Paddies paradox. Med Vet Entomol, 15:1-11.

International Centre for Integrated Mountain Development (ICIMOD), 2017. Land Cover Dynamics in Nepal. International Centre for Integrated Mountain Development, Kathmandu. Available from: http://geoapps.icimod.org/landcover/nepallandcover/ Accessed on: April 2017.

Jarju LB, Fillinger U, Green C, Louca V, Majambere S, Lindsay SW, 2009. Agriculture and the promotion of insect pests: Rice cultivation in river floodplains and malaria vectors in the Gambia. Malar J 8:170.

Jumi LG, 2017. Generalized Linear Models of Malaria Incidence in Jubek State, South Sudan. Sci J App Math Stat 5:134-8.

Kakchapati S, Ardkaew J, 2011. Modeling of Malaria Incidence in Nepal. J Res Health Sci 11:7-13.

Khaemba BM, Mutani A, Bett MK, 1994. Studies of anopheline mosquitoes transmitting malaria in a newly developed highland urban area: a case study of Moi University and its environs. East Afr Med J 71:159-164.

Klinkenberg E, van der Hoek W, Amerasinghe FP, 2004. A malaria risk analysis in an irrigated area in Sri Lanka. Acta Trop 89:215-25.

Koudou BG, Tano Y, Doumbia M, Nsanzabana C, Cissé, G, et al., 2005. Malaria transmission dynamics in central Côte d'Ivoire: the influence of changing patterns of irrigated rice agriculture. Med Vet Entomol 19:27-37.

Lindblade KA, Walker ED, Onapa AW, Katungu J, Wilson ML,
2000. Land use change alters malaria transmission parameters by modifying temperature in a highland area of Uganda. Trop Med Int Health 5:263-74.

Ministry of Agricultural Development (MoAD), 2013. Statistical Information on Nepalese agriculture 2075/76 [2018/19]. Ministry of Agricultural Development, Government of Nepal, Kathmandu. Available from: https://s3-ap-southeast-1.amazonaws.com/prod-gov-agriculture/server-assets/publication1595229368881-0dc12.pdf

Prothero RM, 1999. Malaria, Forests and People in Southeast Asia. Sing J Trop Geog 20:76-85.

Ripert CL, Raccurt CP, 1987. The impact of small dams on parasitic diseases in Cameroon. Parasitol Today 3:287-289.

Sarkar A, Aronson KJ, Patil S, Hugar LB, van Loon GW, 2012. Emerging health risks associated with modern agriculture practices: A comprehensive study in India. Environ Res 115:37-50.

Sharma VP, Srivastava A, Nagpal BN, 1994. A study of the relationship of rice cultivation and annual parasite incidence of malaria in India. Soc Sci Med 38:165-78.

University of California San Francisco (UCSF), 2015. Eliminating Malaria in Nepal. University of California San Francisco, California. Available from: https://globalhealthsciences.ucsf. edu/sites/globalhealthsciences.ucsf.edu/files/pub/nepal2015final.pdf Accessed on: March 2017.

Uddin K, Gilani H, Murthy MSR, Kotru R, Qamer FM, 2015. Forest condition monitoring using very-high-resolution satellite imagery in a remote mountain watershed in Nepal. Mount Res Dev, 35:264-77.

Vanwambeke SO, Lambin EF, Eichhorn MP, Flasse SP, Harbach RE, et al., 2007. Impact of land-use change on dengue and malaria in northern Thailand. EcoHealth 4:37-51.

WHO, 2011. Nepal Malaria Programme Review (7-16 June 2010). World Health Organization Regional Office for South East Asia, New Delhi. Available from: https://apps.who. int/iris/bitstream/handle/10665/205550/B4673.pdf?sequence= 1\&isAllowed=y Accessed on: December 2017.

WHO, 2018. Malaria. World Health Organization, Geneva, Switzerland. Available from: http://www.who.int/mediacentre/factsheets/fs094/en/ Accessed on: January 2018.

WHO, 2019. Malaria. World Health Organization, Geneva, Switzerland. Available from: https://www.who.int/malaria/en/ Accessed on: December 2019.

Yasuoka J, Levins R, 2007. Impact of deforestation and agricultural development on anopheline ecology and malaria epidemiology. Am J Trop Med Hyg 76:450-60. 